\title{
Common knowledge? Business intellectuals, BRIC and the production of knowledge across global finance and international relations
}

Journal Article Accepted at Journal of International Relations and Development, https://www.palgrave.com/gb/journal/41268

\section{Authors}

Stephen Aris is a Visiting Scholar at the Department of Geography and Environment, University of Geneva, and also an editor of the Russian Analytical Digest.

Aglaya Snetkov is Lecturer at the School of Slavonic and East European Studies (SSEES), UCL, and also an editor of the Russian Analytical Digest.

\begin{abstract}
This article engages with the debate about how we come to know IR the way that we do. It seeks to contribute to this research agenda in two, related, ways: Firstly, by highlighting the influence that a previously neglected circuit of practice has on the co-constituted knowledge relationship between Global Finance and IR: the business intellectuals of the Cultural Circuit of Capital (CCC). Secondly, it argues that the Science and Technology Studies' concept of boundary objects is invaluable in accounting for both how IR's "constitutive" theorising is influenced by other circuits of practice and the co-constituted nature of "the international" as an object of investigation. To exemplify both arguments, and how they relate to one another, the article traces the co-constituted operation of the concept of the "BRIC". Following the global financial crisis in 2007/8, the CCC popularized the concept of "BRIC", which then came to operate as a boundary object between IR and Global Finance and in the process impacted on how IR knows "rising powers" and "global governance". Thus, the functionality of BRIC as a boundary object served to provide the business intellectuals of the CCC with constitutive influence on how IR knows its object of study.
\end{abstract}

\section{$\underline{\text { Keywords }}$}

knowledge production; cultural circuit of capital; boundary objects; global finance; BRIC; rising powers.

\section{$\underline{\text { Acknowledgement }}$}

The work on this article was partially supported by the Swiss National Science Foundation, as part of the funded project: "Which region? The politics of the UN Security Council P5 in international security crises" (SNF Project Number: 162925). 
One of the most active research agendas in IR during recent years has been that concerned with investigating the production of knowledge on international politics and security. ${ }^{1}$ As well as examining the content of IR knowledge, this scholarship has also investigated how, by whom and from where it is produced. A number of accounts have been posited, including the role of epistemic communities, ${ }^{2}$ Bourdieusian fields, ${ }^{3}$ or (configurations of) assemblages. ${ }^{4}$ While each of these accounts offers a distinct version of how the circuit of IR knowledge production operates, they all draw some form of distinction between an inside and an outside that is constitutive of the production of distinctly "IR" knowledge. At the same time, these accounts also stress the influence that knowledge produced from outside of IR's communities, fields or assemblages has on how IR is known. In this way, scholars have emphasized how IR as a circuit of knowledge production does not operate in isolation from other circuits, but is rather interconnected with and embedded in wider constitutive relations with other domains, such as economics (Aitken 2011; Goede 2012; Boy, Burgess, and Leander 2011; Kessler 2011), health (Elbe, Roemer-Mahler, and Long 2014) or environmental management (Oels 2013).

This article seeks to contribute to this research agenda in two, related, ways: Firstly, by highlighting the influence that a previously neglected circuit of practice has on the coconstituted knowledge relationship between global finance and IR: business intellectuals. A number of scholars have insightfully outlined how a confluence of formal financial institutions and mainstream economic theory - and the ideas, logics and rationalities they espouse - have come to also hold a constitutive influence on how IR knows its object of investigation (Aitken, 2011; Boy, 2015; de Goede, 2005; Kessler, 2011; Amicelle, 2011; Amoore and de Goede, 2008; Aradau and Munster, 2007; Boy, 2015; de Goede, 2008a; Walker and Cooper, 2011). Following the work of a number Cultural Political Economists (Leyshon et al 2005; Thrift 2005; Moisio

\footnotetext{
${ }^{1}$ For e.g.: Bigo 2002; Slaughter 2004; Leander 2005; Bigo 2011; Berling and Bueger 2013; Bueger 2015; Beaulieu-Brossard 2015

${ }^{2}$ Haas 1992; Adler 1992; Slaughter 2009; Antoniades 2003; Cross 2013

${ }^{3}$ Adler-Nissen, 2011; Berling, 2012; Bigo, 2011; Mérand, 2010; Senn and Elhardt, 2013

${ }^{4}$ Walters, 2014; Bueger, 2015; Bourne, Johnson \& Lisle, 2015; Porter 2012
} 
2018), we suggest that the role of Cultural Circuits of Capital (CCC) have been largely neglected in accounting for how global finance influences IR. Thrift's notion of the CCC draws attention to the influence of a circuit of business analysts, management consultants, management gurus and "financial research analysts" that produce academic-like knowledge about investment opportunities, management theory and indeed the nature of capitalism itself. In line with Moisio (2018), we argue that the knowledge produced and disseminated by the $\mathrm{CCC}$ is constitutively impactful on more than just the world of investment banks. It also extends to shaping understandings of international politics and security.

Secondly, the article argues that the Science and Technology Studies' (STS) concept of boundary objects is analytically useful in accounting for how IR's "constitutive" theorizing (Guzzini 2013, 534; Berenskoetter 2016, 151/2) is influenced by other circuits of practice, in this case by CCCs. The majority of the current literature on IR's knowledge relations to other circuits of practice has focused on the role that the macro rationalities, logics and imaginaries prevalent in these other circuits have had on reconstituting how IR knows the world (Aradau and Munster 2009; Bigo 2002; Salter 2008; Madsen 2011; Rosenberg 2016; Bueger and Bethke 2014). Such macro-dynamics are unquestionably significant, but we note that they are not exhaustive of extra-domain influences on IR knowledge production. Alongside macro-logics and -imaginaries, "external" influences also manifest themselves at more micro-scales of interaction. Drawing on the STS notion of "boundary objects" (Bowker \& Star 2000; Star 2010), we highlight the role that certain concepts can play in embedding distinct circuits of practice in co-constituted knowledge production. Importantly, the notion of a boundary object suggests that a concept neither simply travels from one circuit to the other, nor is it the object of a one-off translation. Rather, certain concepts continue to be co-constituted by multiple circuits due to their dual identity: Firstly, a general one stemming for its common usage by both circuits; And secondly, multiple specific ones developed from its tailored usage by each circuit. This duality ensures an on-going process of constitutive influence from one to the other. As a 
result, boundary objects often operate as the conceptual vocabulary and infrastructure of engagement between circuits of knowledge-production. Importantly for IR, a focus on the role of boundary objects is analytically useful for examining the co-constituted nature of "the international" as an object of investigation. It offers a way to account for how the international's functionally differentiated complexity is rendered both universally and particularly meaningful (Albert 2016; Kessler 2012; Albert and Buzan 2013).

To exemplify both of these arguments, and how they relate to one another, the article sets out an empirical case study that details the emergence and subsequent development of the acronym and concept of the 'BRIC' and the ways in which this has impacted on how IR knows its object of study. In the wake of the global financial crisis in 2007/08, the CCC sought to popularize the concept of the "BRIC" as a propositional knowledge claim about a new type of low risk and high return investment market and an ontic object through which global finance (GF) should be known. Subsequently, this concept entered common usage in circuits of IR knowledge production, but with an altered significance and resonance to reflect the preoccupations of IR. Whilst its usage in IR retained important aspects of the concept of the "BRIC" as popularized by the CCC, such as directing attention towards an inevitable rise in economic growth of four non-Western states. The tailored usage reframed BRIC in terms of its significance for how IR knows "rising powers" and "global governance". Notably, in the late 2000s, BRIC was frequently used in relation to claims and concerns about a shift away from a Western liberal world order to an Eastern authoritarian one: a focus that is specific to IR's usage, but based on an acceptance of common usage in association with the CCC's. Due to this process of shifting back and forth between its common and tailored identity, the BRIC boundary object functioned to give the CCC co-constitutive agency over certain aspects of IR knowledge production. Hence, to account for how BRIC has influenced knowledge about international politics, it is necessary to consider the interplay between how CCCs and IR have used the 
concept. In other words, its role as a boundary object between differentiated circuits of knowledge production

To further articulate these interlinked arguments, this article will, firstly, set out the existing literature on extra-domain influences on IR knowledge production. Secondly, it details the role and influence that the CCC has within GF and on the way IR is known. Thirdly, it outlines the STS concept of a boundary object and the way in which such objects can animate knowledge across circuits of production. Fourthly, and finally, we set out the exemplary case study of BRIC as a boundary object across GF/CCC and IR.

\section{Outside-in influences on IR circuits of knowledge production}

An important area of investigation in IR scholarship during recent decades has been the epistemological and sociological analysis of how knowledge about international politics and security comes to be known and articulated. This scholarship has challenged several key assumptions about mainstream IR. Significantly, it has led to an expansion in who, what and where is considered to be a relevant producer of knowledge on IR, beyond an exclusive focus on the political elites and spokesmen of nation-states and international institutions. Notably, scholars have elucidated the hidden role of security "professionals in charge of the management of risk and fear" (Bigo 2002), including private contractors (Leander \& van Munster 2007; Abrahamsen \& Williams 2007), NGOs (Slaughter 2004; Krahmann 2003) and technocratic elites (Hagmann and Cavelty 2012). This scholarship has also challenged the neat and mutuallyexclusive separation of the analysis and practice of IR. The influence that the academic study of IR, and the theories and exemplars it puts forth, has on the practice of international politics and security has been emphasized (Ish-Shallom 2006; Büger and Villumsen 2007). More recently, the role that non-human objects, technologies and other devices (Bellanova \& González, 2013; Schouten, 2014; Amicelle, Aradau \& Jeandesboz, 2015), play in the production of IR knowledge has been highlighted. 
As well as expanding the scope of the sources, sites and objects considered as relevant to the production of IR knowledge, this research agenda has sought to describe, understand and characterize how the activities and interactions between these practices come together as a circuit(s) of IR knowledge production. Some have emphasized the interaction of an elite group of IR experts in the form of an "epistemic community" (Haas 1992; Adler 1992; Slaughter 2009; Antoniades 2003; Cross 2013). Others have drawn on Bourdieu to describe these various actors as participants in a "field" or "fields" of IR (e.g. Adler-Nissen, 2011; Berling, 2012; Bigo, 2011; Mérand, 2010; Senn and Elhardt, 2013). Relationalist scholars have focused on foregrounding the varied "assemblages" of actants that come together to perform IR (e.g. Walters, 2014; Bueger, 2015; Bourne, Johnson \& Lisle, 2015; Porter 2012).

What these varying standpoints have in common is the notion that the knowledge produced by these circuits of practice can be distinguished from that of other knowledges produced about the world, in a manner akin to the Luhmannian notion of functional differentiation (see Alberts 2016; Kessler 2012; Alberts and Buzan 2013). In other words, IR epistemic community(ies), field(s) and assemblages are seen as producing and performing a knowledge that is distinctly "IR", constituted and made meaningful by its own particular tacit knowledges and preoccupations about its object of investigation. In this way, rendering IR knowable in a way that brings to the fore certain subject positions, responses and questions, while foreclosing others (e.g. Aradau \& van Munster, 2007; Sending \& Neumann 2006; Dillon, 2007).

At the same time, none of these conceptual accounts of IR's circuit of knowledge production close the door on influences from beyond the IR circuit. Accordingly, new actors may enter or even operate across epistemic communities (Cross 2013). Whilst "the boundaries of the different [Bourdieusian] fields and their possible entanglements are constantly shaped and reshaped both by internal struggles and by external interventions of agents of other related fields" (Bigo 2011, 240). And, different configurations of assemblages should be "understood 
as hanging together in a loosely structured social space in the international realm" (Büger and Villumsen 2007, 427). In sum, then, all hold out the possibility, and indeed likelihood, that IR knowledge is produced and shaped by influences from beyond their prescribed version of its circuit of knowledge production.

However, all of them also stress that such outside-in constitutive influences do not impact on IR in the exact same way as their influence on other circuit(s) of knowledgeproduction in which they can be found. Rather, something happens to knowledge entering into IR. This knowledge from other circuits is not simply taken up wholesale, it is translated according to IR's tacit knowledges, codes, centrifugal forces and horizons of propositional knowledge (Bueger 2015; Bueger and Bethke 2014; Stritzel 2012; Bourne, Johnson, and Lisle 2015; Madsen 2011).

Against this background, scholars have sought to examine these "external" influences on the production of knowledge about international political and security (e.g. Aradau and Munster, 2007; Bigo, 2002; Salter, 2008). This has centered on examining how the macro rationalities, logics and modes of operation of other domains of social practice are impactful on, overlap with or mutually productive of IR knowledge production. To this end, scholarly accounts have elucidated the creeping "securitization" of other domains, and their reciprocal constitutive and compositional influence on IR. For example, Stefan Elbe highlights the securitization of global health and the "pharmaceuticalization" of IR (Elbe, 2006, 2008, 2014). Oels $(2012,185)$ has also emphasized "the successful 'climatization' of the security field" and securitization of climate change. And, several scholars have detailed a "financialization" of security and "securitization" of finance (Aitken, 2011; Boy et al., 2011; de Goede, 2012; Kessler, 2011).

Indeed, the latter interest in the co-implicated knowledge and practices of international politics, security and finance has, arguably, received the most attention from IR scholarship. And, it is to this research agenda that this article seeks to contribute. To this end, the next section 
sets out the case for considering CCCs as knowledge-producers of significance to not only global finance, but also IR. We then set out how the STS notion of boundary objects offers an analytically-insightful perspective on the co-constituted nature of knowledge produced about distinct objects of investigations.

\section{Cultural Circuit of Capital: Business intellectuals as producers of abstract}

\section{knowledge on global finance}

While often rhetorically said to be interconnected, IR and GF have largely been addressed by states, international institutions and the academy as differentiated circuits of actors, research questions, publications and objects (Boy et al., 2011; de Goede 2010; Hameiri and Jones, 2015; Kessler, 2011; Kristensen, 2012; Mastanduno, 1998; Moisio 2018; Neocleous, 2006). In recent years, however, various scholars have outlined how the knowledge and practices of IR and GF often cut across this neat binary line of separation between the two domains. In short, they have noted how the circuits of knowledge production on IR and GF are "enmeshed within each other in complicated ways" (Aitken 2011).

Most notably, this research agenda has centered on two interconnected foci. Firstly, how the rationales, logics and modes of operation animating IR and GF influence one another (i.e. that there is a financialization of security and/or securitization of finance) (Aitken, 2011; Boy, 2015; de Goede, 2005; Kessler, 2011). Secondly, how, in practice, they are both the object of the same rationales, logics and modes of operation based on risk and a "governmentality of unease" (Amicelle, 2011; Amoore and de Goede, 2008; Aradau and Munster, 2007; Boy, 2015; de Goede, 2008a; Walker and Cooper, 2011).

In so doing, this scholarship has highlighted the impact that formal GF institutional actors, such as states and international institutions, have on IR (e.g. Neocleous 2006; Mastanduno 1998). Others have investigated the constitutive structuring influence of the financial models, logics and ideologies articulated by the academic discipline of economics, 
such as those related to neoliberalism and risk (e.g. Kessler 2011; Aitken 2011; de Goede 2008; Walker \& Cooper 2011). And indeed, a vibrant agenda has emerged that points to the way that the confluence of formal institutional actors and academic theoreticians of global finance is constitutively-impactful on how IR produces knowledge about international politics and security (e.g. Boy et al. 2011; Hameiri and Jones 2015; Amicelle 2011; de Goede 2010).

Less attention, however, has been devoted to examining how other producers of GF knowledge impact on how IR is known. Alongside central banks, global financial institutions and academic economists, Cultural Political Economy (CPE) scholars argue that there are other significant producers of new knowledge shaping how economies are known. This includes the amorphous role of "business intellectuals". As outlined by Leyshon et al (2005, 428), it is necessary "to extend the range of actors understood to be involved in the construction of economic abstractions beyond academic theorists, to encompass other 'business intellectuals' who are more actively engaged in the commercial world" (Leyshon et al 2005, 428). If GF is an important external knowledge influence on IR, and business intellectuals are notable produces of GF knowledge, then it follows that business intellectuals may have an impact on how IR is known.

In making this argument, we draw on Thrift's concept of the "Cultural Circuit of Capital" (CCC), which directs our attention to a particularly significant circuit of business intellectuals that shape how GF is known. The CCC concept identifies the role played by epistemic circuits of business analysts, management consultants, management gurus and "financial research analysts" in shaping how market and investment are practiced (Leyshon et al 2005, 435). According to Thrift (2005, 12), the activity of this circuit of "business intellectuals" represents a "concerted global discursive operation", which "attempts to describe itself $[\mathrm{CCC}]$ to the world (as the 'knowledge economy'), to persuade itself that this was what the world was like, and to extend this description to the rest of the economy, and indeed to the world at large". 
The knowledge outputs produced by the CCC are for investors and corporate clients. As a result, the CCC tends to produce knowledge orientated more towards immediate use-value than that found in orthodox economics as an academic discipline, by offering simpler and more pragmatic theories, concepts and models. Leyshon et al $(2005,441)$ suggest that the CCC specialize in "half-way abstractions, that are more than examples but are less than theories", based on "practices [that] were lifted out of their context, stabilized through abstraction, transformed into templates for action and then inserted back into practical contexts as a set of ideas to be applied". Indeed, the knowledge produced by the CCC is only considered valuable if it is subsequently taken up by this audience, and usually if they are willing to pay for it in the form of advice, training courses or general consultancy.

In this context, the CCC disseminates its "half-way abstraction" via its activities in teaching at and shaping the curriculum of business schools, the publication of reports that frame discussions and conceptual categories, and consultancy and advisory work for key market players. Through these activities of dissemination, the CCC has "the power to make its theories and descriptions of the world come alive in new built form, new machines and new bodies", akin to a "feedback loop" between the conceptions and practices of GF (Thrift 2005: 11). In this way, the CCC is said to render considerable influence on how financial markets and investment opportunities are conceptualized, and thus how actors practice their engagement with them.

At the same time, the extent of such circuits' influence is not limited to the world of investment firms, business schools and consultancy, or even to state and global financial institutions. As detailed in a recent study of the influence of the $\mathrm{CCC}$ on reconstituting imaginaries of geopolitics, Moisio $(2018,51)$ notes how this "packaged management knowledge" is "consumed not only by business leaders but also, and perhaps more interestingly, by politicians, by policymakers and government officials": all important actors within the circuit of IR knowledge-production. And, indeed, as we seek to show with our case study, the 
CCC had a significant constitutive impact not only on IR "practitioners" via the concept of the BRIC, but also the knowledge produced by academics and think tanks focused on international politics and security. Hence, we posit - following Moisio (2018) - that to account for how global financial knowledge influences the way IR is known, it is necessary to consider not only formal institutions and academic economics, it is "crucial to examine the geopolitical imaginaries of the knowledge-based society as linked to the "cultural circuits of capitalism"" (Moisio 2015, 230).

Building on Moisio's work on the promotion and dissemination of a "hub and flow" imaginary, we suggest that one pathway by which the $\mathrm{CCC}$ renders constitutive influence on the circuit of IR is through the creation of new categorical schema and knowledge-objects. Notably, and as demonstrated by the case of the BRIC in this article, we focus on the way that new concepts that encapsulate a (re)ordering of the world in terms of economic potential and opportunities can also have an impact on how IR is known. We seek to account for how knowledge produced by the CCC can have a co-constitutive influence on IR knowledge production by reference to the STS notion of a "boundary object". The next section, therefore, outlines our understanding of the role that boundary objects can have in knitting together distinct circuits of practices in delimited co-constituted knowledge production.

\section{Boundary Objects: A pathway to common knowledge production across and between distinct circuits of practice}

As outlined above, the question of how our understanding of IR both influences and is influenced by other circuits of practice has been a prominent one in recent years. One particular focus has been on the influence that concepts and categorical schema from other circuits of production can have on IR. This article seeks to highlight that certain concepts do not simply travel from one circuit to the other or are the object of one-time translations on entering a new 
circuit, but create a delimited, and sometimes temporary, pathway of knowledge-exchange and co-production between the circuits they traverse. This pathway is constructed by the operation of a concept that is constituted by both the common usage of all circuits and the particular usages of each circuit. A function that is conceptually accounted by the STS notion of a "boundary object".

The notion of a boundary object describes more than simply the process through which a particular concept is borrowed by one knowledge circuit from another. Although boundary objects "are those objects that both inhabit several communities of practice and satisfy the informational requirements of each of them" (Bowker and Star 1999, 297), they do not have to hold the same significance, role or resonance within each circuit of practice. As Star (2010, 602) outlines, although the way circuits' use and interact with a boundary object "may resemble each other, overlap, and even seem indistinguishable to an outsider's eye", in practice "[t]heir difference depends on the use and interpretation of the object".

Figure 1: Boundary Objects - Tacking back-and-forth between common \& tailored identities

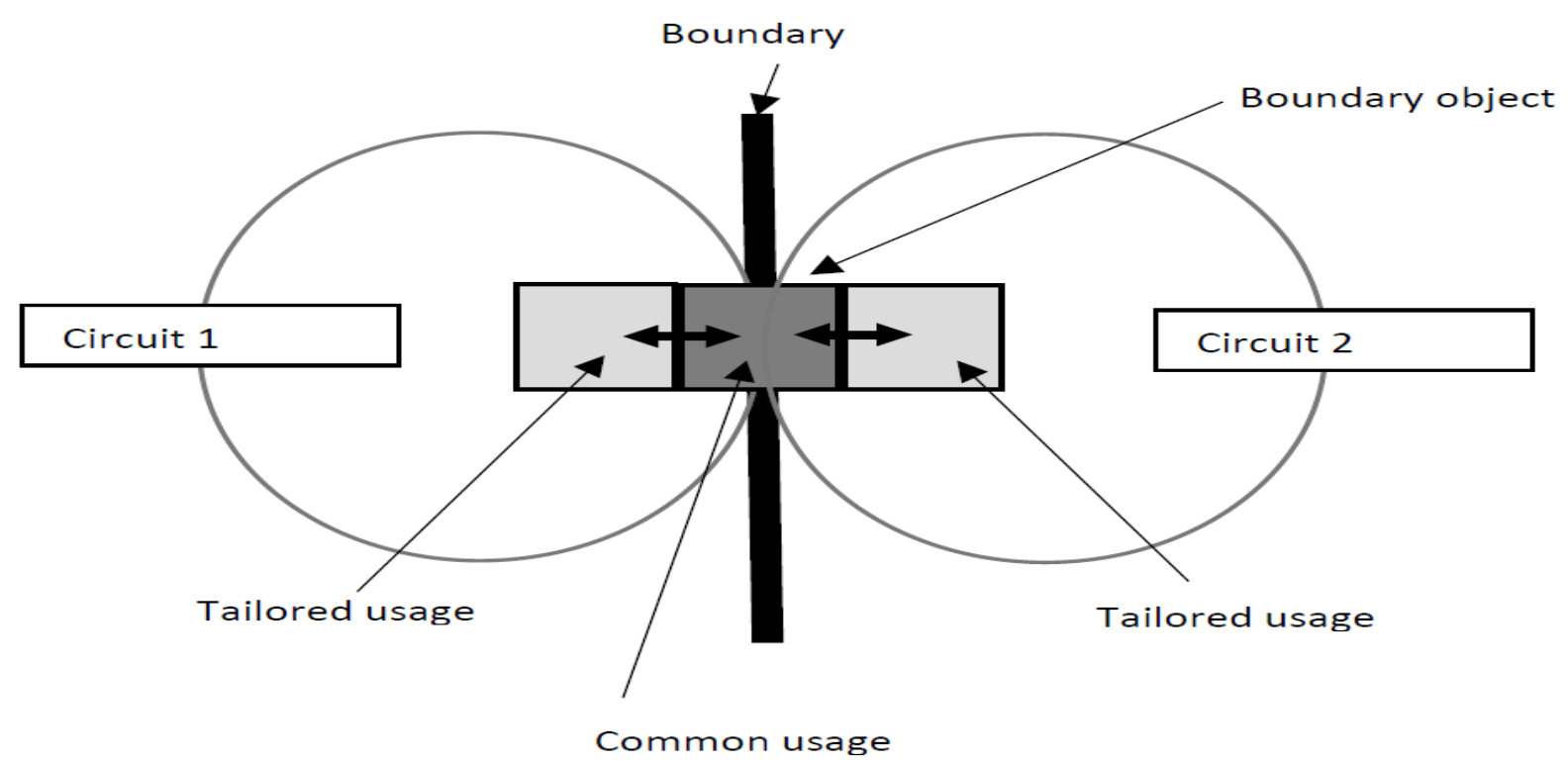


As a result, boundary objects are constituted by - at a minimum - a dual identity: one, a "vaguer identity as a common object" that is observable, usable and, to at least some extent, mutually understandable by circuits on each side of a boundary; and two, a "more specific [identity], more tailored to local use within a social world", which is only fully understood and acted upon by those within each delimited circuit of production. As visualized in figure 1 above, an important implication of this dual identity is that a boundary object binds distinct circuits in co-constitutive practices of knowledge production about this object, because each uses it by "tack[ing] back-and-forth between both [vague/common and specific/tailored] forms of the object" (Star 2010, 604/5). In other words, no individual circuit has full constitutive control of how the boundary object is interpreted, but rather their respective usages has some influence on how it is known in general and, thereby, also on its significance in all others circuit using it. Therefore, the functionality of a boundary object is that of an important source of outside-in and/or inside-out influence on the knowledge relation between two circuits of practice. This conceptual apparatus, thus, provides an account of how a concept created by and popularized among business intellectuals can come to influence how IR produces knowledge in ways that both mirror and are distinct to those articulated by this circuit of business intellectual.

At this point, it should be noted that we follow a symbolic interactionist account of boundary objects that draws no distinction between objects as material and as metaphorical. Rather, the material and metaphorical are seen as inherently bound-up in one another (Büger 2008, 9). Hence, as Fox $(2011,72)$ sets out, “[b]oundary objects can be representations, abstractions or metaphors that have the power to 'speak' to different communities of practice". In other words, a concept, such that of the BRIC, that overlaps two distinct circuits of practice can function to establish an exchange and co-productive relation between the knowledge produced by these circuits.

Although we are seeking to highlight the importance of boundary objects in accounting for the influence of other circuits of practice on IR knowledge production, we are not suggesting 
that such knowledge exchange is of more significance than the co-production of macrorationalities, logics and imaginaries between IR and other circuits of practice that have been outlined by other works (e.g. Aitken, 2011; Boy, 2015; de Goede, 2005; Kessler, 2011). The extent to which boundary objects are productive of co-constituted knowledge between distinct circuits of practices is less all-encompassing than that of macro- and overarching-rationalities, -logics and -imaginaries. Boundary objects establish discrete and delimited modes of outsidein and inside-out knowledge production between circuits, rather than operating to integrate, supplant or transpose rationalities, logics or imaginaries from one to another. In other words, boundary objects shape how new additions to the "unfinished dictionary of the "international"" are rendered IR knowledge (Guzinni 2013, 535; see also Leander 2011; Berenskoetter 2016, 152). In this way, boundary objects can be seen as contributing to the ontic infrastructure of IR knowledge-production.

From this perspective, a focus on the role of boundary objects is particularly analytically useful for examining the co-constituted nature of "the international" as an object of investigation. A focus on boundary objects offers analysts' a way to account for how the functionally differentiated complexity of the international is rendered both universally and particularly meaningful (Albert 2016; Kessler 2012; Albert and Buzan 2013). As the example of the BRIC illustrates, boundary objects can establish new categorical schema and identities within IR knowledge-production, due to their development, dissemination and usage within other circuits of practice. And, thereafter, the interplay of "tacking back-and-forth" between the vaguer identity common to all circuits and the tailored identity uniquely developed by each operates as a continuous co-constitutional process, until such time as the object ceases to be used meaningful in one or all of these circuits. Indeed, Büger (2008) has already demonstrated how the "international development" and "international security" circuits of knowledge production have influenced one another's constitutive accounts of their objects of investigation, via their common and tailored work on the boundary object of "human security". 
Taking this into account, this article now turns to detailing its illustrative example of a boundary object functioning to embed IR and another circuit of practice in co-constituted knowledge-production: the BRIC. The next sections outlines the CCC's co-constitutive impact on how IR is known via its articulation and dissemination of the notion of the BRIC, in particular the impact this had on IR debates around "rising powers" and "global order change" following the global financial crisis in 2007/08 and in the late 2000s.

\section{BRIC: A boundary object co-constituting global financial markets and international politics and security}

The "origin story" of BRIC as a propositional claim and, subsequently, a formalized international club is well known. BRIC was coined in a 2001 report by the Global Economics, Commodities and Strategy Research department at Goldman Sacks, entitled Building Better Global Economic BRICs (O’Neill 2001). Its popularity resulted in its chief author, Jim O’Neill, becoming a highly visible and prominent figure in the business and financial media: a business intellectual. This was followed up, across the 2000s, with further reports and forecasts from the same research team at Goldman Sacks: in 2003, they were "Dreaming With BRICs"; in 2005, asking "How Solid are the BRICS"; in 2009, the BRICs were "Lead[ing] the Global Recovery" and "Drivers of Global Consumption"; and, in 2010, the team reflected on both the global financial crisis and their claims about the BRIC in "BRICs at 8: Strong through the Crisis, Outpacing forecasts". The common thesis across these publications is "that Brazil, Russia, India and China are in a process of overtaking some G7 members" (Wansleben 2013, 458), to such an extent whereby "in less than 40 years, the BRICs economies together could be larger than the G6 in US dollar terms" (Wilson \& Purushothaman 2003).

This activity of producing public knowledge by a research division of a major multilateral global investment bank may be considered as an example of knowledge produced by and disseminated among CCCs (Wansleben 2013). Furthermore, the academic style of the 
reports also chimes with Thrift and Leyshon's (2005) notion that the CCC produces knowledge based on "half-way abstractions". In this way, the Goldman Sack's "BRIC" publications represented a propositional knowledge claim that while drawing on "neoclassical convergence growth models", sought to "reframe investment opportunities in emerging markets", by shaking up “established classifications and expectations” (Wansleben 2013).

As an example of the influence of knowledge produced and disseminated by CCCs, the circulation of BRIC is notable. It came to have a significant constitutive influence on how GF was known and, thus, practiced. As the Financial Times commentator, Gillian Tett (2010) outlines BRIC rapidly found traction among economic analysts as a neat depiction and extension of the notion of "emerging markets", becoming "a near ubiquitous financial term, shaping how a generation of investors, financiers and policymakers view the emerging markets".

The influence that BRIC has had on constituting the tacit knowledge, according to which GF practice is framed, became most apparent following the $2007 / 8$ financial crisis. With the BRIC economies appearing to rebound from the crisis much better that the established "developed" economies, BRIC became the knowledge-object through which the global financial industry sought to plot and project a return to global economic growth and a favorable investment climate. Sum (2013) argues that global capital knowledge-producers leveraged the “"BRIC' imaginary" “[a]s objects of "hope'/'strength"” that could serve as "drivers of recovery in the context of financial crises in the US and Europe". All stories need protagonists, and in this case, the BRIC were singled-out and rendered knowable as the territorial sites and particular actors upon which this recovery story would play out.

An important driver in this respect, according to Sum (2013: 554), was Jim O’Neill's 2007 statement that the "BRIC consumer is going to rescue the world", which was taken up and “popularized by nodal discursive networks of top investment advisers....and fund managers... in the mass and internet media". As Wansleben $(2013,463)$ details, this also manifested itself 
in an increase in both portfolio flows to the BRIC economies, and the creation of a number of "BRIC funds" by major investment institutions during the mid-to-late 2000s. In short, exemplifying claims by Cultural Political Economists (CPE) about the power and influence of the CCC in structuring knowledge about and practices in GF.

Figure 2: Journal articles publications with "BRIC" in title, abstract or keywords by discipline, 2008-16

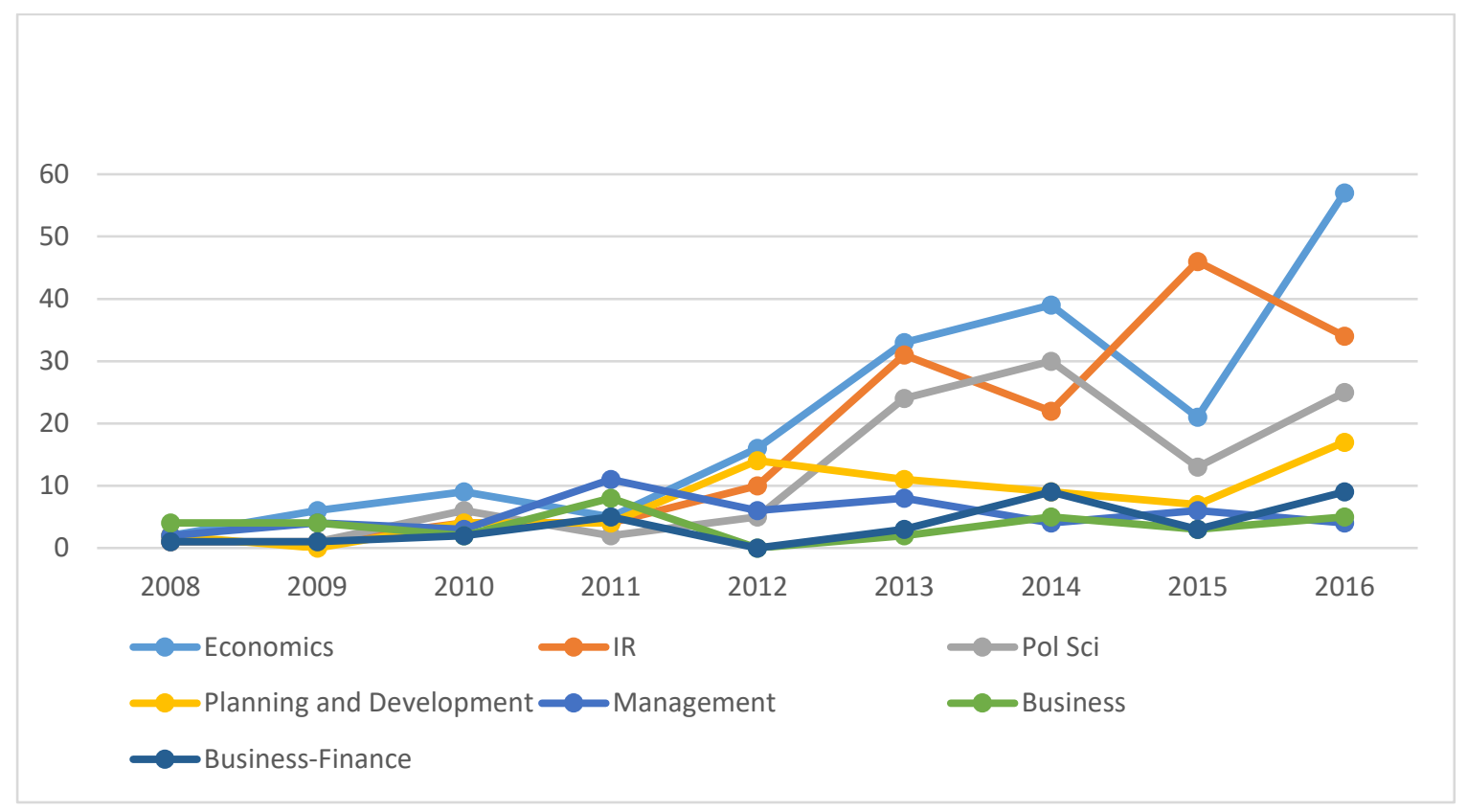

Source: Thompson Web of Science

However, it was not only an increase in the flow of investments to the BRIC economies that correlated with the increasingly prominence and circulation of the BRIC knowledge object within the CCC. Figure 2, above, details the usage of "BRIC" or "BRICS" in the titles, abstracts and keywords of articles, books, chapters and reviews in the Web of Science database's disciplinary categories of "Economics", "Business-Finance" and "Management". As this graph visualizes, BRIC has been used more and more frequently in GF-related academic publications since the global financial crisis. This bears out Thrift's (2005) assertion about the agency of the 
non-academic knowledge producers of $\mathrm{CCCs}$ in constructing and circulating abstract knowledge, which extends to shaping academic economic orthodoxy that thereafter constitutes how markets are known.

Although it was constructed for and initially circulated within the circuits of GF, the resonance of BRIC has been felt beyond this domain, particularly in IR. Indeed, some of the CPEs who have traced BRIC's circulation within GF have also noted the concurrent effect it has had on how IR circuits come to know the world. Sum (2013: 555) notes that "[p]olicymakers, international organizations, think tanks, foreign policy analysts, etc., warmed to the affective ecological space of the BRIC imaginary". In addition, the political elites of the named states themselves engaged with and repurposed the concept to create a formal framework for cooperation and coordination around the notion of the BRIC. With the creation of the BRIC Annual Summit Forum in 2009, a new institutional forum was born. Indeed, not only do Brazilian, Russian, Indian and Chinese foreign policy discourses frequently refer to their status and identity as BRIC, and now BRICS, states (Thakur and Cooper, 2014), but they also articulate a common program and agenda on global politics, finance, governance and security around the concept.

Aside from such elite diplomatic circuits of knowledge production, the notion of BRIC has also been increasingly used in other key circuits of IR knowledge production, as illustrated by Figure 2. Although there are fewer "IR" than "economics" publications in the Web of Science database, usage of the notion BRIC by IR publications is almost on a par with those in economics, and is well above its cognizant disciplinary categories of business, finance and management. Furthermore, a search of the Harvard Kennedy School's (google-powered) Think Tank publication database for "BRIC" or "BRICS" returned nearly 150,000 results in April 2017, many of which are reports and policy briefs about the BRIC's impact on international politics, governance and security. 
Taking the above together, we can say that the BRIC knowledge object, initially generated by the CCC and circulating within GF, has become a commonly known and relatively frequently used propositional knowledge claim in the production of knowledge about IR.

\section{Figure 3: BRIC as a boundary object between GF and IR}

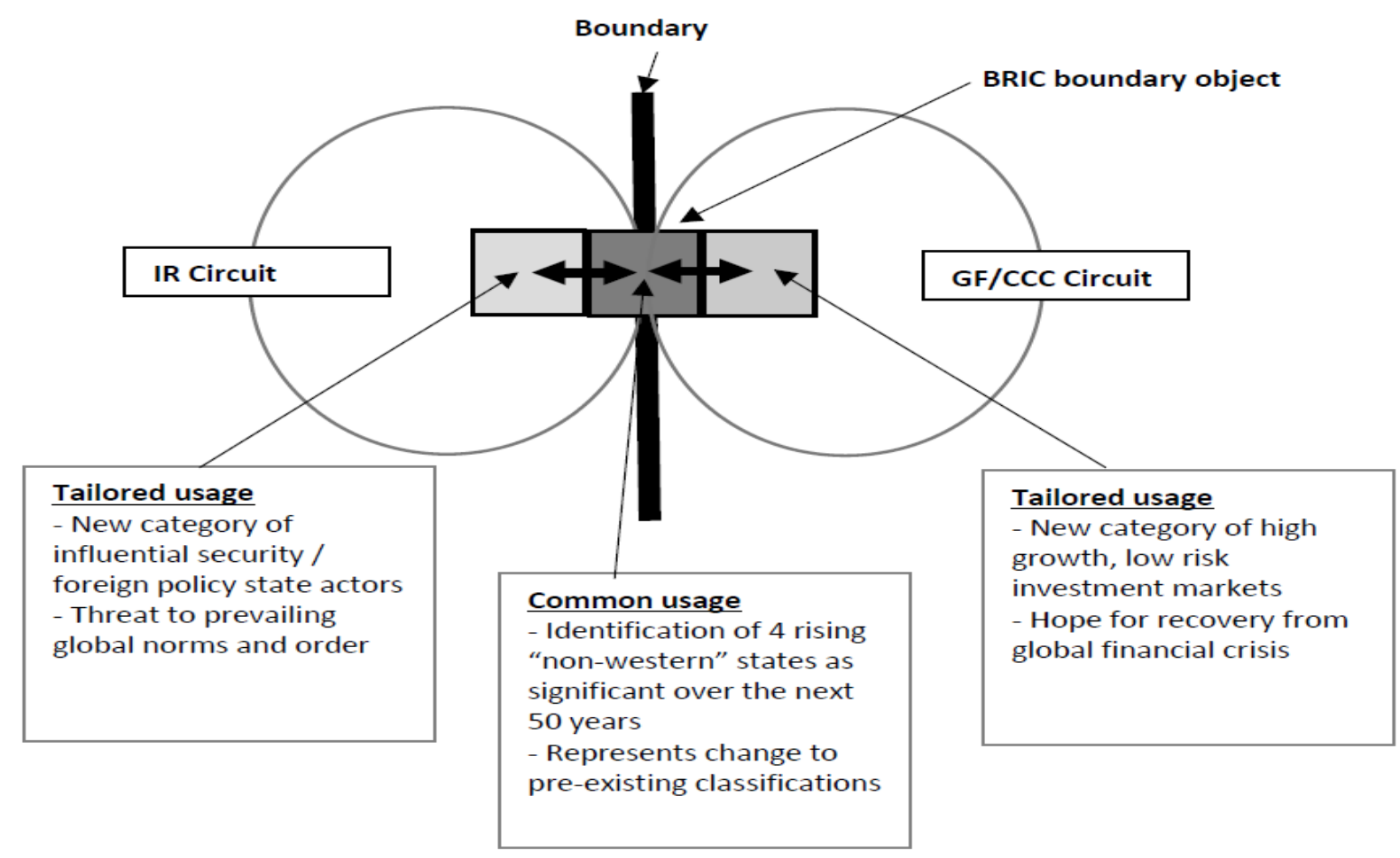

However, the concept of the BRIC was not imported from GF into IR in a one-to-one transfer. It came to function as a boundary object between IR and GF/CCC, which functioned as a pathway for each to influence the knowledge produced in the other. Following Star's (2010) conceptualization of the operation of boundary objects and as visualized in figure 3 above, we interpret this influence as part of the "tacking back and forth" by the circuits of GF/CCC and IR between their "common" and, respective, "tailored" usages of it. From this standpoint, we highlight the co-constitutive impacts that the BRIC boundary object came to have on IR: Firstly, the particularization and territorialization of an abstract process of "global order change"; 
Secondly, the reconsideration and re-categorization of the conceptual classifications producing their objects of investigation; And, thirdly, the formulation of new practices of association.

\section{Naming "global order change”}

As the circuit in which it was originally coined and popularized, the $\mathrm{CCC}$ has had a strong influence on the "common identity" of BRIC as a boundary object. Nonetheless, as its usage in IR increased, the concept also acquired a particular "tailored identity" reflecting IR's tacit knowledge and orientations. This "tailored identity" was distinct from its "common identity" as a boundary object. While this common usage revolved around the notion of an ongoing shift in the trajectory of global affairs writ large, the interpretation of the implications of this global shift diverged between the tailored usages of the CCC and IR, respectively. Within CCCs, its usage centered on shifting global market conditions and investment opportunities. Whereas for IR, its tailored usage was situated within a wider IR narrative about the "global order change" supposedly underway in world affairs. Its transition from a concept operating primarily in GF to that of a boundary object that is co-constituted by GF and IR was particularly evident in the comment of the CPE, Leon Wansleben (2013: 454), who noted that: "[ $t$ ]he most surprising development [about the circulation of BRIC among the $\mathrm{CCC}$ ], however, is....political scientists and commentators discuss BRICS in the context of a potential change from a unipolar (US led) to a multipolar global order". This statement recognizes the way that a boundary-object circulates beyond its initial circuit of production, and, as a result, takes on new forms and significance due to the work of other circuits using it.

Within IR's tailored usage of the concept, the BRIC states were depicted as a group of state foreign policy actors with growing power and capacity to shape global order and governance, rather than as a source of new investment opportunities. Indeed, as "one of the most popular attempts to shape the way we understand rising non-established powers" (Stuenkel, 2011), BRIC became an important entity within the object-inventory of IR 
knowledge about shifts in global power and order. In this context, Cox (2012) suggests "[i]t has become the new truth of the early twenty-first century that the Western world we have known is fast losing its pre-eminence to be replaced by a new international system shaped either by the so-called BRICs comprising Brazil, Russia, India and China, the 'rest', or more popularly by that very broadly defined geographical entity known as Asia". In this way, BRIC has become part of the knowledge circulating in IR, in particular among "experts" that play the role of providing abstract knowledge for explaining what is occurring in their object of investigation: international politics and security.

As such, the BRIC boundary object became known in IR in a way that projected the CCC's claims about an increase in economic growth in the BRIC states onto an increase in their political standing. This was, in turn, assumed to lead to an effort by these states to challenge the prevailing international order (Burrows and Harris, 2009; Iley and Lewis, 2011; Roberts, 2009; Roubini, 2009; Subacchi, 2008), and alter the "rules of the game" in their favor (Laïdi, 2012; Layne, 2012). Hence, this tailored usage was only possible due to the work of the CCC in establishing the "common identity" of BRIC as an acronym identifying the key states (economies) that will grow in medium-term to become influential players in the world. This “common identity" was, however, reworked into a "tailored identity" for IR usage. The upshot of this work on tailoring the common identity of BRIC to IR was to identify and foreground a key question: Will this phenomenon lead to change or continuity in the current institutional arrangements and norms of practice in global governance? (see for e.g. Brütsch and Papa 2013). With variations of this question addressed across a range of topic-areas relating to IR, including energy (Downie, 2015), R2P and international interventions (Ralph and Gallagher, 2015), and the governance of cyber-space (Mueller et al., 2013). Correspondingly, the BRIC states were often presented in terms of being a "threat" in IR, as compared with a source of "hope" in GF. However, this smooth translation of the CCC notion of BRIC into IR has not been without its challengers. Indeed, the CCC's propositional claim about the BRIC's medium-term 
growth prospects and the work of IR circuits in tailoring this claim to correspond to a wider narrative about a shift in the global "balance-of-power" has been dismissed by some as a “fallacy” (Pant, 2013) or "geopolitical fad" (Brütsch \& Papa, 2013). It was also simply ignored by others. Hence, there has been resistance within IR circuits to the acceptance of the BRIC as a boundary object that is co-constitutive of how IR and GF are known. Or, in other words, push back against this work "tacking back and forth" between common and tailored usages of BRIC, ensuring that this process is messy, contested and far from universally transformative. Yet, even by contesting its validity and relevance, the usage of BRIC in IR is indicative of its operation as a boundary object, which renders certain - common and distinct - knowledge effects on how both GF and IR are known. A process of knowledge production that, thus, provides Goldman Sacks and the CCC a form of constitutive influence, albeit mediated and sometimes resisted, on IR knowledge production.

\section{Reclassifying the analytical categories of the international}

As outlined above, the co-constituted common usage of BRIC within both GF and IR centers on the construction of a new entity within the ontology of the international: the BRIC state as a distinct type. In relation to this common identity as a new classificatory type of state, each also developed a tailored usage of BRIC - as a new investment opportunity and a revisionist rising power - within each of their respective circuits of production. In turn, different conclusions and implications were drawn with regard to their respective objects of investigation, and the practices they inform.

As it circulated as a strategic narrative of "hope" following the 2007/8 financial crisis, BRIC served to alter, or at least to challenge, the pre-exiting classificatory regimes constituting the object of GF. During much of the previous 30-40 years, GF practice was premised on a commonly accepted wisdom that international investment markets were constituted by a binary differentiation between "developed" and "developing" economies. The former being associated 
to "low credit risk" with a limited scope for return and the latter offering the prospect of greater reward, but at a greatly increased "credit risk". However, "the BRICs concept breaks open traditional classifications" (Wansleben 2013: 455). In other words, the developed/developing paradigm. As it was promoted and circulated by the CCC, BRIC functioned to change how global investment was known by bringing a new object to the attention of GF circuits of practice: four economies that are neither "developed" (as high growth economics AND as offering high financial returns), nor "emerging" (as large and stable economies AND as offering solid long-term opportunities) (Wansleben 2013). The new "BRIC" category opened the way to both "new investment opportunities" and the set the stage and classificatory order for "the emergence of a new cultural circuit of capital of post-emerging market investments to developing economies" (Wansleben 2013).

Following its transition to operating as a boundary object across GF and IR, BRIC had a similar constitutive influence on the analytical categories by which IR is known. As part of a wider reorientation of knowledge about IR from that of the post-Cold War notion of the "end of history" and Western-liberal hegemony towards a focus on global order change and "rising powers", BRICs was used to draw attention to a new type of non-Western state, with increasing power and influence on global order and governance. In this way, BRIC functioned as a new categorical entity in the ontology of international politics and security.

As suggested by Cooper (2010) "calling rising powers IBSA, BRICs or BRICSAM makes a difference about not just the shape of our mental map about emerging powers, but how the diplomatic behavior of these actors is taken as playing out in practice". Indeed, BRIC has often been used in the analysis of international politics and security as a new categorical entity. For example, analysis of the proclaimed phenomenon of the ascent of "rising powers" to challenge Western hegemony has often been reduced to the perspective of the role of the BRIC states. This is evident in its use as a shorthand for the common characteristics and collective 
interests of the named states, and, as such, as a common typology: BRIC foreign policy and security actors (Sil, 2014; Stephen, 2014).

Furthermore, the BRICs are often compared and contrasted to the West as distinct categorical groupings of state actors. This most frequently relates to their positions and stances on key questions, norms and crises of global governance, such as national sovereignty (Laïdi, 2012), R2P (Morris, 2013), strong state-led policy-making (Stephen, 2014), international institutions (Ikenberry and Wright, 2008), governance of the internet (Mueller, Schmidt and Kuerbis, 2013) and status concerns vis-à-vis the West and the US in particular (Larson and Shevchenko, 2010; Stuenkel, 2011). From this vantage point on how contemporary IR is known, Burges (2015) suggests that during recent years "foreign policy-makers and their academic interlocutors have been able to count on a stock question during almost any discussion of global governance and international order: what about the BRICS?"

As the above suggests, BRIC's circulation as a boundary object across GF and IR operated according to its common identity as a new object that altered the way both see their object of investigation. In this sense, IR and GF both reacted to one another's tailored usage in co-constituting this common identity, with IR referring directly to its usage in GF more frequently than vice versa. However, the concept of the BRIC was rendered intelligible in both circuits in ways predominantly in line with their, respective, tailored work. Hence, the circuits of GF and IR both drew upon their particular prevailing knowledge to use BRIC to inscribe and enroll this new conceptual object into, and reclassify, their respective objects of investigation: either as a new form of "emerging market" in which high return, low risk investments are possible; or as a new type of "foreign policy and security actor" intent on and able to reshape global order and governance. 
The CCC's efforts in popularizing BRIC saw it come to operate as a boundary object that not only impacted on how academic and policy analysts in IR know their object of investigation, but it also informed how political elites, especially those of the named states, know the world and frame their understanding of their choices and actions. After establishing greater contact with one another as a group on an informal level within the framework of the UN General Assembly, the BRIC Summit Forum (which in 2011 became "BRICS" with the inclusion of a fifth country: South Africa) was formally established. Indeed, the adoption and repurposing of the CCC's concept by the political elites of the BRIC states was openly acknowledged by Russian Foreign Minister, Sergei Lavrov in April 2009, when he noted that that the idea for the BRIC[S] Summit Forum came 'from statistical handbooks'. While the official website for the $5^{\text {th }}$ BRICS Summit notes it origins lie in "an economic modelling exercise to forecast global economic trends over the next half century". Hence, this represents tailored work on the BRIC boundary object by the political elites of the BRIC states. This tailored work also impacted on the resonance, significance and productive effects of the common identity of BRIC. And, hence, how it has been used by circuits of GF and IR knowledge production.

With the creation of a multilateral forum under its name, the BRIC[S] has come to stand for a certain political identity and agenda around a sense of commonality and patterns of association among these states, as well as an optimistic economic forecast and the notion of being the same kind of foreign policy actor. This includes joint abstract political calls for a less Western-centric world, a more equitable architecture of global security and economic governance, a greater voice for "rising powers" (see Thakur and Cooper, 2014) and the need for establishing a 'fairer and more democratic international system in general' (Medvedev, 2010). More specific policy prescriptions are also evident, such as the creation of the BRICS Development Bank, common foreign policy statements and suggestions that the dollar's tenure as the sole international reserve currency should be ended (BRIC Summit 2009). Indeed, the recent establishment of the BRICS Development Bank has been widely seen as attempt to 
provide an alternative to, and challenge the predominance of, the World Bank and IMF as the foremost multilateral institutions of global economic governance (Chin, 2014; Stuenkel, 2013; Tierney, 2014).

At the same time, the significance and efficacy of the BRICS as a political identity and multilateral forum should not been overstated. The BRIC[S] label remains both vague and lacking in concrete practices. Indeed, many IR scholars and analysts have questioned both the commonality of the BRIC[S] identity/agenda and the degree of agreement and efficacy of the BRICS forum as multilateral framework (Pant 2013; Brütsch and Papa 2013). Yet, irrespective of its long-term viability, functionality and output, the creation of a multilateral forum represents a significant performative impact for a knowledge claim put forward by a Goldman Sachs research report only a few years previous. Indeed, the BRIC forum's practices of producing and performing a new collective political identity, regularized contact, a common agenda and various collaborative policy initiatives, funds and institutions would seem to be both informed by, and serving to inform, the usage of BRIC in both GF and, especially, IR academic and policy analysis circuits of knowledge production.

\section{Conclusion}

The circulation of the concept of BRIC, from its origins within a pseudo-academic report popularized by business intellectuals to its impact on how IR knows "rising powers" and "global order change", is illustrative of this article's two, related, arguments about the co-constitutive influence of other circuits of practices on IR knowledge production. Firstly, that to account for the influence that GF has on how IR is known and practiced, it is necessary to consider not only formal institutions and mainstream economic theory and models, but also the theories, concepts and claims produced and circulated by Cultural Circuits of Capital. Secondly, that boundary objects operate to create pathways for such co-constitutive knowledge production between IR and other circuits of practice. 
In the article's case study, these two arguments come together to explain how IR and the CCC are engaged in a co-constitutive knowledge relationship around the concept of the BRIC. Following the CCC's coining and dissemination of the concept, BRIC was also frequently used within IR. Subsequently, and as detailed above, it came to function as a boundary object between GF/CCC and IR. Whilst initially adopting the common identity of the concept, which was predominantly shaped by the CCC, IR also developed a more tailored identity of BRIC in line with its own dispositions as its usage of the concept increased. However, this tailored version did not simply overwrite the common one, but rather the tailored and common identities entered into a dialogical relationship with one another. In other words, IR and the $\mathrm{CCC} / \mathrm{GF}$, as circuits of practice, engaged in a co-constitutive knowledge production relationship, around the delimited space of the concept of BRIC.

Hence, the interaction between IR's and GF's tailored usage of BRIC produced a common ontic object that named and particularized a shift in global affairs and the BRIC state as a new type of object. This, in turn, was productive of the tailored usage of BRIC in GF as a reason for "hope" of a global financial recovery, by introducing a new classification of investment market that was neither developed, nor developing. While in IR, BRIC was used as an embodiment of a process of global order change away from the "West", by drawing attention to a new classificatory type of "non-Western" and "rising power" foreign policy actor, with an interest in reordering global governance. The process of "tacking back-and-forth" between these common and tailored usages served as a mechanism through which elements of the BRIC knowledge animating both GF and IR was co-constituted by one another.

As the example of the BRIC boundary object demonstrates, knowledge produced by the "business intellectuals" of the CCC can, and at times does, hold a very significant influence on how IR knows the world. Indeed, as various CPE's have outlined, the role that CCCs play in framing not just financial markets and investments, but also the wider world should not be underestimated. The knowledge formulated and promoted by business intellectuals, and the 
popular management theories they espouse, have proven influential and wide-reaching within contemporary political-economic contexts. This extends to cover the traditional concerns of IR: international politics and security. In this way, as Moisio $(2018,7)$ reminds us, the CCC can exert an important influence on the articulation and dissemination of the "hub and flow" imaginaries that are challenging the supremacy of "territorial power" imaginaries in informing the "contemporary geopolitical condition". Therefore, it is important that we take into account the knowledge produced by the CCC in efforts to explain how IR knows the international in the way that it does.

Furthermore, we also advocate a greater awareness of the role that boundary objects play in connecting, and operating as modes of co-constitutive knowledge produce between IR and other circuits of practice. By its very nature, IR's object of investigation - the international - is shared or at least overlaps with many other circuits of practice (e.g. GF, society, health and environment). And, hence, knowledge about the international is often co-constituted by these multiple circuits of practice. Although, typically, boundary objects represent less fundamental and sustained modes for the co-production of knowledge across circuits, if compared with the extensive impact of interactions between the underlying rationalities, logics or imaginaries of the distinct circuits of the international. They, nonetheless, represent a significant and frequent relation of co-constituted knowledge production between circuits within a delimited knowledge space, as in the case of the BRIC. What is more, boundary objects offer us a way to account for the multiplicity of usages of knowledge-objects, such as concepts, within, across and between the differentiated circuits of practices that constitute the international. And, therefore, boundary objects are significant in explaining how we know the international, simultaneously, as either a social whole and as a set of differentiated objects of investigations. From this standpoint, this article argues that scholarship on IR knowledge production needs to take into account the coproductive, -implicated and -constitutive role that boundary objects play in the knowledge relations between IR and the other circuits of practice that compose the international. 



\section{Bibliography}

Abrahamsen, Rita and Michael C. Williams (2007) 'Securing the City: Private Security Companies and Non-State Authority in Global Governance', International Relations 21(2): $237-253$.

Adler, Emanuel (1992) 'The emergence of cooperation: national epistemic communities and the international evolution of the idea of nuclear arms control', International Organization 46(1): 101-145.

Adler-Nissen, Rebecca (2011) 'On a Field Trip with Bourdieu', International Political Sociology 5(3): 327-330.

Aitken, Rob (2011) 'Financializing security Political prediction markets and the commodification of uncertainty', Security Dialogue 42(2): 123-141.

Albert, Mathias (2016) A Theory of World Politics, Cambridge University Press.

Albert, Mathias and Barry Buzan (2013) 'International Relations Theory and the "Social Whole”: Encounters and Gaps Between IR and Sociology’, International Political Sociology 7(2): 117-135.

Amicelle, Anthony (2011) 'Towards a “new” political anatomy of financial surveillance', Security Dialogue 42(2): 161-178.

Amicelle, Anthony, Claudia Aradau, and Julien Jeandesboz (2015) 'Questioning security devices: Performativity, resistance, politics', Security Dialogue 46(4): 293-306. 
Amoore, Louise and Marieke De Goede (2008) 'Transactions after 9/11: the banal face of the preemptive strike', Transactions of the Institute of British Geographers 33(2): 173185.

Antoniades, Andreas (2003) 'Epistemic Communities, Epistemes and the Construction of (World) Politics', Global Society 17(1): 21-38.

Aradau, Claudia and Rens Van Munster (2007) 'Governing Terrorism Through Risk: Taking Precautions, (un)Knowing the Future', European Journal of International Relations 13(1): 89-115.

Aradau, Claudia and Rens van Munster (2009) 'Exceptionalism and the "War On Terror" Criminology Meets International Relations', British Journal of Criminology: azp036.

Beaulieu-Brossard, Philippe (2015) 'Bypassing the reflexivity trap: IR's disciplinary status and the politics of knowledge', International Relations 29(2): 263-266.

Bellanova, Rocco and Gloria González Fuster (2013) 'Politics of Disappearance: Scanners and (Unobserved) Bodies as Mediators of Security Practices', International Political Sociology 7(2): 188-209.

Berenskoetter, Felix (2017) ‘Approaches to Concept Analysis', Millennium 45(2): 151-173.

Berling, Trine Villumsen (2012) ‘Bourdieu, International Relations, and European security’, Theory and Society 41(5): 451-478.

Berling, Trine Villumsen and Christian Bueger (2013) 'Practical Reflexivity and Political Science: Strategies for Relating Scholarship and Political Practice', PS: Political Science \& Politics 46(01): 115-119. 
Bigo, Didier (2002) 'Security and Immigration: Toward a Critique of the Governmentality of Unease', Alternatives: Global, Local, Political 27(1): S63.

Bigo, Didier (2011) 'Pierre Bourdieu and International Relations: Power of Practices, Practices of Power', International Political Sociology 5(3): 225-258.

Bourne, Mike, Heather Johnson, and Debbie Lisle (2015) 'Laboratizing the border: The production, translation and anticipation of security technologies', Security Dialogue 46(4): 307-325.

Bowker, Geoffrey C. and Susan Leigh Star (2000) Sorting Things Out: Classification and Its Consequences, MIT Press.

Boy, Nina (2015) 'Sovereign safety', Security Dialogue 46(6): 530-547.

Boy, Nina, J. Peter Burgess, and Anna Leander (2011) 'The global governance of security and finance Introduction to the special issue', Security Dialogue 42(2): 115-122.

Brütsch, Christian and Mihaela Papa (2013) 'Deconstructing the BRICS: Bargaining Coalition, Imagined Community, or Geopolitical Fad?', The Chinese Journal of International Politics: pot009.

Bueger, Christian (2015) 'Making Things Known: Epistemic Practices, the United Nations, and the Translation of Piracy', International Political Sociology 9(1): 1-18.

Bueger, Christian and Felix Bethke (2014) 'Actor-networking the "failed state" — an enquiry into the life of concepts', Journal of International Relations and Development 17(1): $30-60$. 
Büger, Christian and Trine Villumsen (2007) 'Beyond the gap: relevance, fields of practice and the securitizing consequences of (democratic peace) research', Journal of International Relations and Development 10(4): 417-448.

Burges, Sean W. (2015) 'The BRICS and the future of global order. By Oliver Stuenkel', International Affairs 91(4): 878-879.

Burrows, Mathew J. and Jennifer Harris (2009) 'Revisiting the Future: Geopolitical Effects of the Financial Crisis', The Washington Quarterly 32(2): 27-38.

Chin, Gregory T. (2014) 'The BRICS-led Development Bank: Purpose and Politics beyond the G20', Global Policy 5(3): 366-373.

Cooper, A.F. (2010) 'Labels Matter: Interpreting Rising Powers through Acronyms', in A. F. Cooper and Alan S. Alexandroff, eds., Rising States, Rising Institutions: Challenges for Global Governance, Centre for International Governance Innovation.

Cox, Michael (2012) 'Power Shifts, Economic Change and the Decline of the West?', International Relations 26(4): 369-388.

Cross, Mai'a K. Davis (2013) 'Rethinking epistemic communities twenty years later', Review of International Studies 39(01): 137-160.

Dillon, Michael (2007) 'Governing through contingency: The security of biopolitical governance', Political Geography 26(1): 41-47.

Downie, Christian (2015) 'Global energy governance: do the BRICs have the energy to drive reform?', International Affairs 91(4): 799-812.

Elbe, Stefan (2006) 'Should HIV/AIDS Be Securitized? The Ethical Dilemmas of Linking HIV/AIDS and Security', International Studies Quarterly 50(1): 119-144. 
Elbe, Stefan (2008) 'Risking Lives: AIDS, Security and Three Concepts of Risk', Security Dialogue 39(2-3): 177-198.

Elbe, Stefan, Anne Roemer-Mahler, and Christopher Long (2014) 'Securing circulation pharmaceutically: Antiviral stockpiling and pandemic preparedness in the European Union', Security Dialogue 45(5): 440-457.

Fox, Nick J. (2011) 'Boundary Objects, Social Meanings and the Success of New Technologies', Sociology 45(1): 70-85.

Goede, Marieke De (2005) Virtue, Fortune, And Faith: A Geneaology Of Finance, University of Minnesota Press.

Goede, Marieke de (2012) Speculative Security: The Politics of Pursuing Terrorist Monies, U of Minnesota Press.

Guzzini, Stefano (2013) 'The ends of International Relations theory: Stages of reflexivity and modes of theorizing', European Journal of International Relations 19(3): 521-541.

Haas, Peter M. (1992) 'Introduction: epistemic communities and international policy coordination', International Organization 46(1): 1-35.

Hagmann, Jonas and Myriam Dunn Cavelty (2012) 'National risk registers: Security scientism and the propagation of permanent insecurity', Security Dialogue 43(1): 7996.

Hameiri, Shahar and Lee Jones (2015) 'Probing the links between political economy and nontraditional security: Themes, approaches and instruments', International Politics 52(4): 371-388. 
Iley, Richard A. and Mervyn K. Lewis (2011) 'Has the global financial crisis produced a New World Order?', Accounting Forum 35(2): 90-103.

Ish-Shalom, Piki (2006) 'Theory as a Hermeneutical Mechanism: The Democratic-Peace Thesis and the Politics of Democratization', European Journal of International Relations 12(4): 565-598.

Kessler, Oliver (2011) 'Beyond sectors, before the world Finance, security and risk', Security Dialogue 42(2): 197-215.

Kessler, Oliver (2012) 'World Society, Social Differentiation and Time', International Political Sociology 6(1): 77-94.

Krahmann, Elke (2003) ‘Conceptualizing Security Governance', Cooperation and Conflict 38(1): 5-26.

Kristensen, Peter M. (2012) 'Dividing Discipline: Structures of Communication in International Relations', International Studies Review 14(1): 32-50.

Laïdi, Zaki (2012) 'BRICS: Sovereignty power and weakness', International Politics 49(5): $614-632$.

Larson, Deborah Welch and Alexei Shevchenko (2010) 'Status Seekers: Chinese and Russian Responses to U.S. Primacy', International Security 34(4): 63-95.

Layne, Christopher (2012) 'This Time It's Real: The End of Unipolarity and the Pax Americana', International Studies Quarterly 56(1): 203-213.

Leander, Anna (2005) 'The Power to Construct International Security: On the Significance of Private Military Companies', Millennium - Journal of International Studies 33(3): $803-825$. 
Leander, Anna and Rens van Munster (2007) 'Private Security Contractors in the Debate about Darfur: Reflecting and Reinforcing Neo-Liberal Governmentality', International Relations 21(2): 201-216.

Leigh Star, Susan (2010) 'This is Not a Boundary Object: Reflections on the Origin of a Concept', Science, Technology, \& Human Values 35(5): 601-617.

Leyshon, Andrew, Shaun French, Nigel Thrift, Louise Crewe, and Peter Webb (2005) 'Accounting for e-commerce: abstractions, virtualism and the cultural circuit of capital', Economy and Society 34(3): 428-450.

Löwy, Ilana (1992) 'The Strength of Loose Concepts - Boundary Concepts, Federative Experimental Strategies and Disciplinary Growth: The Case of Immunology', History of Science 30(4): 371-396.

Madsen, Mikael Rask (2011) 'Reflexivity and the Construction of the International Object: The Case of Human Rights1', International Political Sociology 5(3): 259-275.

Mastanduno, Michael (1998) 'Economics and Security in Statecraft and Scholarship', International Organization 52(04): 825-854.

Mérand, Frédéric (2010) 'Pierre Bourdieu and the Birth of European Defense', Security Studies 19(2): 342-374.

Moisio, Sami (2015) 'Geopolitics/Critical Geopolitics', in The Wiley Blackwell Companion to Political Geography, 220-234, Wiley-Blackwell.

Moisio, Sami (2018) Geopolitics of the Knowledge-Based Economy, Routledge. 
Mollinga, Peter P. (2010). 'Boundary concepts for interdisciplinary analysis of irrigation water management in South Asia', ZEF Working Paper Series available at https://www.econstor.eu/handle/10419/88380.

Morris, Justin (2013) 'Libya and Syria: R2P and the spectre of the swinging pendulum', International Affairs 89(5): 1265-1283.

Mueller, Milton, Andreas Schmidt, and Brenden Kuerbis (2013) 'Internet Security and Networked Governance in International Relations', International Studies Review 15(1): 86-104.

Neocleous, Mark (2006) 'From Social to National Security: On the Fabrication of Economic Order', Security Dialogue 37(3): 363-384.

Oels, Angela (2005) 'Rendering climate change governable: From biopower to advanced liberal government?', Journal of Environmental Policy \& Planning 7(3): 185-207.

O’Neill, Jim (2001) 'Building Better Global Economic BRICs', Global Economics Paper No. 66. (Goldman Sachs).

Pant, Harsh V. (2013) 'The BRICS Fallacy', The Washington Quarterly 36(3): 91-105.

Porter, Tony (2012) 'Making serious measures: numerical indices, peer review, and transnational actor-networks', Journal of International Relations and Development 15(4): 532-557.

Ralph, Jason and Adrian Gallagher (2015) 'Legitimacy faultlines in international society: The responsibility to protect and prosecute after Libya', Review of International Studies 41(03): 553-573. 
Roberts, Cynthia (2009) 'Russia’s BRICs Diplomacy: Rising Outsider with Dreams of an Insider', Polity 42(1): 38-73.

Rosenberg, Justin (2016) 'International Relations in the prison of Political Science', International Relations 30(2): 127-153.

Roubini, Nouriel (2009) 'Another BRIC in the Wall?', Project Syndicate available at http://www.project-syndicate.org/commentary/another-bric-in-the-wall (accessed 24 July, 2015).

Salter, Mark B. (2008) 'Imagining Numbers: Risk, Quantification, and Aviation Security', Security Dialogue 39(2-3): 243-266.

Schouten, Peer (2014) 'Security as controversy: Reassembling security at Amsterdam Airport', Security Dialogue 45(1): 23-42.

Sending, Ole Jacob and Iver B. Neumann (2006) 'Governance to Governmentality: Analyzing NGOs, States, and Power', International Studies Quarterly 50(3): 651-672.

Senn, Martin and Christoph Elhardt (2013) 'Bourdieu and the bomb: Power, language, and the doxic battle over the value of nuclear weapons', European Journal of International Relations: 1354066113476117.

Sil, Rudra (2014) 'Which of the BRICs Will Wield the Most Influence in Twenty-Five Years? Russia Reconsidered', International Studies Review 16(3): 456-460.

Slaughter, Anne-Marie (2009) A New World Order, Princeton University Press.

Stephen, Matthew D. (2012) 'Rising regional powers and international institutions: the foreign policy orientations of India, Brazil and South Africa', Global Society 26(3): 289-309. 
Stritzel, Holger (2012) 'Securitization, power, intertextuality: Discourse theory and the translations of organized crime', Security Dialogue 43(6): 549-567.

Stuenkel, Oliver (2011) 'Identity and the concept of the West: the case of Brazil and India', Revista Brasileira de Política Internacional 54(1): 178-195.

Subacchi, Paola (2008) 'New power centers and new power brokers: are they shaping a new economic order?', International Affairs 84(3): 485-498.

Sum, Ngai-Ling (2013) ‘A cultural political economy of crisis recovery: (trans-)national imaginaries of "BRIC" and subaltern groups in China', Economy and Society 42(4): $543-570$.

Sum, Ngai-Ling and Bob Jessop (2013) Towards a Cultural Political Economy: Putting Culture in its Place in Political Economy, Edward Elgar Publishing.

Tett, Gillian (2001) 'The story of the Brics'. Financial Times, January 15.

Thakur, Ramesh and Andrew F. Cooper (2014) 'The BRICS in the New Global Economic Geography', Routledge.

Thrift, Nigel (2005) Knowing Capitalism, SAGE.

Tierney, Michael J. (2014) 'Rising Powers and the Regime for Development Finance', International Studies Review 16(3): 452-455.

Walker, Jeremy and Melinda Cooper (2011) 'Genealogies of resilience From systems ecology to the political economy of crisis adaptation', Security Dialogue 42(2): 143-160.

Walters, William (2014) 'Drone strikes, dingpolitik and beyond: Furthering the debate on materiality and security', Security Dialogue 45(2): 101-118. 
Wansleben, Leon (2013) “"Dreaming with BRICs”', Journal of Cultural Economy 6(4): 453471.

Wilson, D. \& Purushothaman, R. (2003) “Dreaming with BRICs: The Path to 2050”, Global Economics Paper No. 99 (Goldman Sachs). 